\title{
Differential IFN-Gamma (IFN- $\gamma)$, Interleukin 10 (IL-10) and Cardiac Troponin I (cTnI) Responses in Natural Bovine Trypanosomosis in Nigeria
}

\author{
Michael I. Takeet ${ }^{1,2,3 *}$, Benjamin 0. Fagbemi ${ }^{3}$, Sunday O. Peters ${ }^{4,5}$, Matthew Wheto ${ }^{6}$, \\ Abdulmojeed Yakubu7, Marcos DeDonato ${ }^{1,8}$, Ikhide G. Imumorin' \\ ${ }^{1}$ Animal Genetics and Genomics Laboratory, International Programs, College of Agriculture and Life Sciences, \\ Cornell University, Ithaca, NY, USA \\ ${ }^{2}$ Department of Veterinary Microbiology and Parasitology, Federal University of Agriculture, Abeokuta, Nigeria \\ ${ }^{3}$ Department of Veterinary Microbiology and Parasitology, University of Ibadan, Ibadan, Nigeria \\ ${ }^{4}$ Department of Animal Science, Berry College, Mount Berry, GA, USA \\ ${ }^{5}$ Department of Animal and Dairy Sciences, University of Georgia, Athens, GA, USA \\ ${ }^{6}$ Department of Animal Breeding and Genetics, Federal University of Agriculture, Abeokuta, Nigeria \\ ${ }^{7}$ Department of Animal Science, Nasarawa State University, Lafia, Nigeria \\ ${ }^{8}$ Department of Biomedicine, Universidad de Oriente, Cumana, Venezuela \\ Email: "takeetmi@funaab.edu.ng
}

Received 21 May 2016; accepted 9 July 2016; published 12 July 2016

Copyright (C) 2016 by authors and Scientific Research Publishing Inc.

This work is licensed under the Creative Commons Attribution International License (CC BY).

http://creativecommons.org/licenses/by/4.0/

c) (i) Open Access

\section{Abstract}

Trypanosomosis is major drawback to profitable livestock production in sub-Sahara African, including Nigeria. Knowledge of the cytokines production in the phase of natural infection may help to better diagnose, treat and prevent bovine trypanosomosis. The purpose of the this study was to determine the levels of interferon-gamma (IFN- $\gamma$ ), interleukin-10 (IL-10) and cardiac troponin-I (cTnI) in the sera of cattle naturally infected with T. brucei, $T$. congolense and $T$. vivax and correlate these levels with parasitaemia and PCV of the infected animals. Five milliliter of blood samples were collected via the jugular vein from 411 randomly selected cattle into EDTA and non-citrated bottle. PCV was determined manually using HCT. Trypansomes were detected and characterized by microscopy and PCR, respectively. Serum levels of IFN- $\gamma$, IL-10 and cTnI were determined using commercial ELISA kit. Data were summarized using descriptive statistic and significance of differences determined by ANOVA. Of the 62 samples positive for trypanosomes by microscopy, $\mathbf{5 0}$ samples were confirmed to species level by PCR. The sera levels of IFN- $\gamma$, IL-10 and cTnI of infected

"Corresponding author.

How to cite this paper: Takeet, M.I., Fagbemi, B.O., Peters, S.O., Wheto, M., Yakubu, A., DeDonato, M. and Imumorin, I.G. (2016) Differential IFN-Gamma (IFN- $\gamma$ ), Interleukin 10 (IL-10) and Cardiac Troponin I (cTnI) Responses in Natural Bovine Trypanosomosis in Nigeria. Open Journal of Veterinary Medicine, 6, 105-111. http://dx.doi.org/10.4236/ojvm.2016.67014 
cattle were higher than non-infected cattle. The differences were not significant $(p<0.05)$ from the non-infected cattle except IL-10. There was no correlation between assayed parameters, the PCV and parasitemia. This is the first report that determines the sera levels of IFN- $\gamma$, IL-10 and cTnI in cattle with natural trypanosomosis. Further investigation is required to understand the specific effect of trypanosomes on myocardiac integrity and interaction between the two cytokines in natural trypanosomosis in cattle.

\section{Keywords}

Cattle, Cardiac Troponin, Interferon-Gamma, Interleukin-10, Trypanosomosis

\section{Introduction}

Trypanosomosis is a major disease complex that has caused great set back to profitable farming in sub-Saharan African. The disease complex is caused majorly by T. brucei brucei, T. congolense and T. vivax in cattle [1] [2]. Cattle are differentially susceptible to $T$. brucei, $T$. congolense and $T$. vivax infections [3]-[5] but the mechanism of susceptibility or resistance is not fully understood.

It is generally believed that response to African animal trypanosomoses involves Type-I and/or Type-II immune response [6], or a combination of both against infection(s) of trypanosomes. Interferon gamma (IFN- $\gamma$ ) and interleukin-2 (IL-2) are the main cytokines produced in Type-I immune response while IL-4, IL-5, IL-6, IL-9 and IL-10 are mainly produced in Type-II immune response. Though, different reports are available on the roles of Type-I and Type-II immune responses in different animal trypanosomosis model, the reports are contradicting [7]-[9]. While proliferation of trypanosomes is said to decreased in mice treated with anti-IFN- $\gamma$ [10] [11] and IFN- $\gamma$ gene deficiency [10], other reports indicate that IFN- $\gamma$ stimulates trypanosome proliferation [12]. Furthermore, most reports on the immune responses in animals to trypanosomoses are experimental murine models [13]-[15], few are available on experimental bovine T. congolense infections [16]-[20] and no report is available on immune responses of animals to T. vivax infection.

Cardiac troponin I (cTnI) is a very sensitive biomarker for assessing the cardiac status [21]. It is considered "gold standard" for the non-invasive diagnosis of myocardial injury in human and animal diseses. But no work has been done to assess the effect of trypanosomosis on the serum level of cTnI in infected cattle.

In Nigeria, single and mixed infections of Trypanosomoses have been reported [2], but reports on the immune responses of cattle to trypanosomoses caused by $T$. brucei brucei, $T$. congolense and $T$. vivax are minimal, where it exists, it is experimental report [22]. To the best of our knowledge no data is available on cytokines and cTnI responses to natural bovine trypanosomosis. This study therefore, quantified the serum levels of interferon gamma (IFN- $\gamma$ ), interleukin-10 (IL-10) and cardiac troponin (cTnI) in cattle that were naturally infected with $T$. brucei, T. congolense and T. vivax, and also associated the effect of parasitaemia and PCV on the serum levels of the assayed cytokine and cTnI.

\section{Materials and Methods}

\subsection{Study Population}

A total of 411 cattle consisting of 308 cattle kept under traditional management system of free grazing (nomadic) and 103 cattle from various abattoirs and slaughter slabs were randomly selected for sampling between October and December, 2010. Those animals that tested positive for trypanosomes by microscopy and confirmed by polymerase chain reaction (PCR) were selected for this study. The study was approved by the Ethical Committee of the College of Veterinary Medicine, Federal University of Agriculture, Abeokuta, Nigeria.

\subsection{Sample Collection}

Blood samples were collected from the jugular vein of each cattle into $5 \mathrm{ml}$ tubes containing ethylene diamine tetraacetic acid (EDTA) as anticoagulant and $5 \mathrm{ml}$ tubes without the EDTA for serum analysis. The samples were transported in mobile refrigerator to the laboratory within 3 hours of collection. The blood samples without the 
anticoagulant were set on tray slanted and allowed to stay for 24 hours in the laboratory for serum harvest. Sera were collected in clean and sterile eppendorf tubes and stored in $-20^{\circ} \mathrm{C}$ freezer until use while the blood, in the EDTA bottles were stored at $4^{\circ} \mathrm{C}$ prior to parasitological examination and DNA extraction.

\subsection{Parasitological Diagnosis and PCV Determination}

Parasitemia was determined using rapid matching method [23]. From each tubes containing anticoagulant, blood was transfer into three capillary tubes which were sealed at one end with plasticin. The capillary tubes were spun in microhaematocrit centrifuge, Haematospin 1400 (Hawksley and Son Ltd. UK) at $220 \mathrm{~g}$ for 5 minutes at room temperature. After centrifugation, the packed cell volume (PCV) was determined using hematocrit reader. The buffy coat and upper most layer of red blood cells of one capillary tube was extruded onto a microscope slide and examined with a phase-contrast microscope (Olympus CX21, Pennsylvania, USA) at $\times 400$ magnification for the presence motile trypanosomes. Not less than 50 fields were examined before positive or negative was declared for each sample. While the haematocrit centrifugation technique (HCT) positive samples were further processed as thin smear stained with Giemsa (EMD Chemicals, USA) for trypanosome species identification, thick blood smear was also prepared, stained with Giemsa and all examined under $\times 100$ oil immersion objective lens ( $\times 1000$ magnification).

\subsection{DNA Extraction and PCR Diagnosis}

DNA was extracted from the blood in EDTA bottle using Quick-gDNA ${ }^{\mathrm{TM}}$ MiniPrep (Zymo Research Corporation, Irvine, CA 92614, U.S.A ) as described by the manufacturer. The primers sets (Bioneer Inc, USA); TBR1 \& 2, TCS1 \& 2, TCF1 \& 2, TCK1 \& 2 and ILO1264 \& 1265, as shown in Table 1, were selected for amplification of T. brucei, T. congolense-savannah, T. congolense-forest, T. congolense-kilifi and T. vivax DNA, respectively. Polymerase chain reaction amplification was performed in $20 \mu \mathrm{l}$ final reaction volume containing equivalent of $20 \mathrm{ng}$ of genomic DNA, $10 \mathrm{mM}$ Tris- $\mathrm{HCl}, \mathrm{pH} 8.3,1.5 \mathrm{mM} \mathrm{MgCl}, 50 \mu \mathrm{M} \mathrm{KCl}, 200 \mu \mathrm{M}$ each of dNTPs, $40 \mathrm{ng}$ of each of the primers and 1unit of Thermus aquaticus DNA polymerase (Bioneer USA) as described in the previous work [2]. Ten microliter of the PCR products were electrophoresed through $1 \%$ agarose gel in $1 \times$ TAE (40 mM TRIS-acetate and $1 \mathrm{mM}$ EDTA) at $90 \mathrm{~V}$ for $80 \mathrm{~min}$. along with $10 \mu \mathrm{l}$ of biological marker, GENEMate Quanti-Marker 100 bp DNA ladder (BioExpress, UT, USA). Gels were stained with GelRedR Nucleic Acid Stain (PHENIX Research Product, Candler, NC, USA) at $5 \mu \mathrm{l} / 100 \mathrm{ml}$ of the agarose gel suspension. After electrophoresis, the PCR products were visualized using ultra violet transilluminator (Spectroline ${ }^{\mathrm{R}}$ TC $312 \mathrm{E}$ ). The PCR products of T. brucei, T. vivax and T. congolense (savannah and forest) strains were sequenced using Big dye Terminator Cycle Sequencing Kit (Applied Biosystems, Foster City, CA, USA) and the sequences were aligned with available published sequences of Trypanosoma species from GenBank.

Table 1. Names and sequences of primers set optimized for Trypanosoma species detection.

\begin{tabular}{|c|c|c|c|}
\hline Parasite target & Primer designation & Primer sequences 5'-3' & References \\
\hline \multirow[t]{2}{*}{ T. brucei } & TBR 1 & CGAATGAATAAACAATGCGCAGT & \\
\hline & TBR 2 & AGAACCATTTATTAGCTTTGTGC & Masiga et al. (1992) \\
\hline \multirow[t]{2}{*}{ T. congolense (s) } & TCS 1 & AGA ACC ATT TAT TAG CTT TGT GC & \\
\hline & TCS 2 & CGAGCGAGAACGGGCAC & Majiwa and Otieno (1990) \\
\hline \multirow[t]{2}{*}{ T. congolense (f) } & TCF 1 & GGACACGCCAGAAGGTACTT & \\
\hline & TCF 2 & GTTCTCGCACCAAATCCAAC & Masiga et al. (1992) \\
\hline \multirow[t]{2}{*}{ T. congolense $(\mathrm{k})$} & TCK 1 & GTGCCCAAATTTGAAGTGAT & \\
\hline & TCK 2 & ACTCAAAATCGTGCACCTCG & Masiga et al. (1992) \\
\hline \multirow[t]{2}{*}{ T. vivax } & ILO 1264 & CAGCTCGCCGAAGGCCACTTGGCTGGG & \\
\hline & ILO 1265 & TCGCTACCACAGTCGCAATCGTCGTCTCAAGG & Masake et al. (1997) \\
\hline
\end{tabular}

Note: T. congolense (s); T. congolense savannah-type, T. congolense (f); T. congolense forest-type and T. congolense (k); T. congolense kilifi-type. 


\subsection{Quantification of Cytokines (IFN- $\gamma$ and IL-10) and Cardiac Troponin-I (cTnI)}

Cytokines and the cardiac troponin I were quantified in serum. Bovine Interferon-gamma (IFN- $\gamma$ ) ELISA was carried out using AbD serotec Bovine Interferon- $\gamma$ ELISA kit (Catalog number MCA5638KZZ), interleukin-10 (IL-10) ELISA was carried out using Cusabio Biotech Co., Ltd. IL-10 ELISA kit (Catalog number CSBE12917B) and Cardiac troponin I ELISA was carried out using Life Diagnostic, Incorporation diagnostic ELISA kit (Catalog number 2010-8-HS) following manufacturer's suggested protocols as contained in the kit manuals. The absorbance at $450 \mathrm{~nm}$ was measured with micro-titer plate ELISA reader ( BioTek ELx 800, Highland Park, USA) and the concentration of the cytokines and the cardiac troponin in each well was calculated by comparison with a standard curve plotted using Microsoft excel program.

\subsection{Statistical Analysis}

Data were presented as the mean \pm SEM. Significance of differences was determined by ANOVA and association within the measured parameters was done using Pearson correlation analysis in SPSS version 19 software. Differences were considered significant at $p<0.05$.

\section{Result}

\subsection{Parasitological and PCR Results}

Parasite detection using microscopy observation showed 62 samples infected by one or more species of trypanosomes. Out of this, 14, 19 and 25 samples were single infection of T. brucei, T. congolense-savannah type and T. vivax, respectively. Using PCR, 7, 22 and 21 of those samples detected as single infections by parasitology were confirmed as T. brucei, $T$. congolense(s) and T. vivax, respectively.

\subsection{Parasitaemia and PCV}

The mean \pm SEM parasitaemia of infected and non-infected cattle were not significantly different. The mean \pm SEM of PCV of T. vivax-infected cattle was relatively lower than T. brucei and T. congolense-infected cattle, but non-infected cattle was had highest PCV that significantly different from others (Table 2).

\subsection{Interferon Gamma (IFN- $\gamma$ )}

The serum levels of interferon gamma (IFN- $\gamma$ ) of T. brucei, $T$. congolense, $T$. vivax and non-infected cattle were $0.022 \pm 0.002 \mathrm{pg} / \mathrm{ml}, 0.219 \pm 0.183 \mathrm{pg} / \mathrm{ml}, 0.065 \pm 0.023 \mathrm{pg} / \mathrm{ml}$ and $0.018 \pm 0.005 \mathrm{pg} / \mathrm{ml}$, respectively. Though the serum IFN- $\gamma$ values of infected cattle were generally higher than non-infected cattle, the changes were not significantly different $(p=0.412)$. There was no correlation between the levels of interferon gamma expressed in the serum and, the PCV and the parasitaemia $(r=-0.134$ and -0.15$)$

\subsection{Interleukin-10 (IL-10)}

The mean sera levels of Interleukin-10 (IL-10) of T. brucei, T. congolense, T. vivax and non-infected cattle were $13.75 \pm 11.95 \mathrm{ng} / \mathrm{ml}, 11.44 \pm 18.05 \mathrm{ng} / \mathrm{ml}, 16.28 \pm 20.27 \mathrm{ng} / \mathrm{ml}$ and $41.56 \pm 34.64 \mathrm{ng} / \mathrm{ml}$, respectively. While there was no significant $(p>0.05)$ different between the mean values of interleukin-10 of the trypanosome infected cattle, the mean values of infected cattle were significantly lower $(p=0.049)$ than non-infected cattle.

Table 2. Parasitaemia and the PCV of trypanosomal infected cattle.

\begin{tabular}{ccr}
\hline Infection & \multicolumn{2}{c}{ Parameter } \\
\cline { 2 - 3 } Trypanosoma brucei & Parasitaemia (mean \pm SEM) & $32.8 \% \pm 3.25 \%$ \\
Trypanosoma congolense(s) & $2.31 \times 10^{6} \pm 1.02 \times 10^{6}$ & $33.1 \% \pm 2.59 \%$ \\
Trypanosoma vivax & $5.13 \times 10^{5} \pm 1.45 \times 10^{6}$ & $30.8 \% \pm 2.08 \%$ \\
\hline
\end{tabular}

Note: Trypanosoma congolense(s); Trypanosoma congolense savannah-type. 
There was no correlation between the levels of interleukin-10 expressed in the serum and the PCV and the parasitaemia ( $r=0.048$ and 0.122$)$.

\subsection{Cardiac Troponin (cTrI)}

The mean values of serum cTrI of $T$. brucei, $T$. congolense, $T$. vivax and non-infected cattle were $0.11 \pm 0.02$ $\mathrm{ng} / \mathrm{ml}, 0.14 \pm 0.07 \mathrm{ng} / \mathrm{ml}, 0.16 \pm 0.42 \mathrm{ng} / \mathrm{ml}$ and $0.10 \pm 0.03 \mathrm{ng} / \mathrm{ml}$, respectively. Though the serum cTnI values of infected cattle were generally higher than non-infected cattle, the changes were not significantly different $(p=$ 0.44). There was no correlation between the levels of cardiac troponin expressed in the serum and, the PCV and the parasitaemia $(r=-0.187$ and 0.008$)$.

\section{Discussion}

The immune response to African animal trypanosomoses has been studied extensively in experimental mice and bovine model, but no attention has been paid to natural infections in cattle. In this study, we assessed the level of interferon-gamma (IFN- $\gamma$ ), interleukin-10 (IL-10) and cardiac troponin-I (cTnI) in the sera of naturally infected cattle in Nigeria.

The circulating levels of IFN- $\gamma$ and IL-10 assayed in this study, exhibited relatively higher levels in the infected cattle than non-infected cattle. Though, report on the plasma/serum level of IFN- $\gamma$ and IL-10 in naturally infected cattle is not available. [6] [14] Reported elevated and decreased levels of IFN- $\gamma$ in highly susceptible BALB/c and resistant C57BL/6 mice, respectively, infected with $T$. congolense, [5] reported significantly higher plasma IL-10 and IFN- $\gamma$ levels in BALB/c mice infected with STIB247 strain of T. brucei. Though these reports are all from murine trypanosomosis model, they are in agreement with our findings except the report of [14]. However, in experimental bovine trypanosomoses, emphasis had been more on T. congolense infections [1] [18] [20] than T. vivax infection [24]. IFN- $\gamma$ increased significantly in experimental $T$. congolense-infected cattle [25] [26], but the increase in T. vivax-infected cattle was small and transitory [24] whereas IL-10 is elevated in susceptible Boran and trypanotolerant N'Dama cattle infected with $T$. congolense [27]. These reports are in partial agreement with our findings as we recorded significant changes in the levels of IL-10 when compared with the non-infected cattle.

The serum levels of cTnI of infected cattle were slightly elevated than the levels in non-infected cattle. This finding could not be compared due to paucity of data. Though, cTnI level in the serum of cattle naturally or experimentally infected with trypanosomes, has not been documented up to date in Nigeria and elsewhere, it's increase has been reported in bovine theileriosis [28], canine babesiosis, ehrlichiosis and canine heart worm diseases [29]-[31]. We reported higher levels of cTnI in infected cattle than non-infected cattle. Contrary to our expectation, the increase was highest in T. vivax infection, a strict intravascular parasite, than infection of $T$. congolense and T. brucei, both which are capable individually, of attaching to red cells and extravascular foci, respectively. Neither PCV nor parasitaemia had positive correlation with the levels of cytokines and cTnI measured in this study, a finding that is in variant with the report of [32] who indicated that increased levels of cytokines are associated with anemia.

We report for the first time in Nigeria the sera levels of cardiac troponin-I (cTnI) and cytokines (IFN- $\gamma$ and IL-10) in natural bovine trypanosomoses. Elevation of cardiac troponin may be an indication of myocardiac injury due to trypanosomes. Both cytokines measured were higher than non-infected animals. This is suggestive of both cytokine being critical in immune-modulation in bovine trypanosomoses. The significantly higher serum levels of IL-10 than IFN- $\gamma$ in the infected animals support the recent report of [13], who indicated that murine trypanosomosis elicit both Type I and Type II immune responses. The process involves sequential switch from Type I cytokine (IFN- $\gamma$ and TNF- $\alpha$ ) production during the early stage of infection to Type II cytokine (IL-10 and/or IL-4) production during the late stage of infection.

\section{Conclusion}

In this study, we provide information on serum levels of IL-10, IFN- $\gamma$ and cTnI in natural bovine trypansomosis. However, the low number of animals considered and absence of follow up makes further investigation imperative to ascertain the specific effect of trypanosomes on myocardiac integrity and interaction between the two cytokine in natural bovine trypanosomosis. 


\section{Acknowledgements}

Financial support provided by the Educational Trust Fund of the Federal Republic of Nigeria and College of Agriculture and Life Sciences at Cornell University, Ithaca, NY, USA is gratefully acknowledged. We also thank the entire staff of the Department of Parasitology and Entomology, Faculty of Veterinary Medicine, Ahmadu Bello University, Zaria, Nigeria for permission granted to use their laboratory facilities for part of this study, with special gratitude to Prof. I. A. Lawal and Dr. O. O. Okubanjo.

\section{References}

[1] O’Gorman, G.M., Park, S.D.E., Hill, S.E.W., Meade, K.G., Coussens, P.M., Agaba, M. Naessens, J., Kemp, S.J. and MacHugh, D.E. (2009) Transcriptional Profiling of Cattle Infected with Trypanosoma congolense Highlights Gene Expression Signatures Underlying Trypanotolerance and Trypanosusceptibility. BMC Genomics, 10, 207. http://dx.doi.org/10.1186/1471-2164-10-207

[2] Takeet, M.I., Fagbemi, B.O., De Donatos, M., Yakubu, A., Rodulfo, H.E., Peters, S.O., Wheto, M. and Imumorin, G.I. (2013) Molecular Survey of Pathogenic Trypanosomes in Naturally Infected Nigerian Cattle. Research in Veterinary Science 94, 555-561. http://dx.doi.org/10.1016/j.rvsc.2012.10.018

[3] Paling, R.W., Moloo, S.K., Scott, J.R., Gettinby, G., McOdimba, F.A. and Murray, M. (1991) Susceptibility of N'Dama and Boran Cattle to Sequential Challenges with Tsetse-Transmitted Clones of Trypanosoma congolense. Parasite Immunology, 13, 427-445. http://dx.doi.org/10.1111/j.1365-3024.1991.tb00295.x

[4] Naessens, J. (2006) Bovine Trypanotolerance: A Natural Ability to Prevent Severe Anaemia and Haemophagocytic Syndrome? International Journal for Parasitology, 36, 521-528. http://dx.doi.org/10.1016/j.ijpara.2006.02.012

[5] Morrison, L.J., McLellan, S., Sweeney, L., Chan, C.H., MacLeod, A., Tait, A. and Turner, C.M.R. (2010) Role for Parasite Genetic Diversity in Differential Host: Responses to Trypanosoma brucei Infection. Infection and Immunity, 1096-1108. http://dx.doi.org/10.1128/IAI.00943-09

[6] Noel, W., Gh, G.H., Raes, G., Namangala, B., Daems, I., Brys, L., Brombacher, F., De Baetselier, P. and Beschin, A. (2002) Infection Stage-Dependent Modulation of Macrophages Activation in Trypanosoma congolense-ResistantSusceptible Mice. Infection and Immunity, 70, 6180-6187. http://dx.doi.org/10.1128/IAI.70.11.6180-6187.2002

[7] Inoue, I.N., Kuriki, M.K., Nagasawa, Y.H., Mikami, T., Fujisaki, K., Suzuki, N. and Hirumi, H. (1999) Interleukin 4 Is a Crucial Cytokine in Controlling Trypanosoma brucei gambiense Infection in Mice. Veterinary Parasitology, 86, $173-$ 184. http://dx.doi.org/10.1016/S0304-4017(99)00143-0

[8] Namangala, B., De Baetselier, P., Noël, W., Brys, L., Magez, S. and Beschin, A. (2001) Relative Contribution of IL-10 and IFN- $\gamma$ towards Resistance to African Trypanosomosis. The Journal of Infectious Diseases, 183, 1794-1800. http://dx.doi.org/10.1086/320731

[9] Shi, M., Wei, G., Pan, W. and Tabel, H. (2006) Experimental African Trypanosomiasis: A Subset of Pathogenic, IFN$\gamma$-Producing, MHC Class II-Restricted CD4+ T Cells Mediate Early Mortality in Highly Susceptible Mice. The Journal of Immunology, 176, 1724-1732. http://dx.doi.org/10.4049/jimmunol.176.3.1724

[10] Bakhiet, M., Olsson, T., Edlund, C., Hojeberg, B., Holmberg, K., Lorentzen, J. and Kristensson, K.A. (1993) Trypanosoma brucei brucei-Derived Factor That Triggers CD8+ IYMPHOCYTES to Interferongamma Secretion: Purification, Characterization and Protective Effects in Vivo by Treatment with a Monoclonal Antibody against the Factor. Scandinavian Journal of Immunology, 37, 165-178. http://dx.doi.org/10.1111/j.1365-3083.1993.tb01753.x

[11] Uzonna, J.E., Kaushiki, R.S., Gordon, J.R. and Tabel, H. (1999) Cytokines and Antibody Responses during Trypanosoma congolense Infections in Two Inbred Mouse Strains That Differ in Resistance. Parasite Immunology, $21,57-71$. http://dx.doi.org/10.1046/j.1365-3024.1999.00202.x

[12] Hertz, C.J. and Mansfield, J.M. (1998) Resistance to the African Trypanosomes is IFN- $\gamma$ Dependent. The Journal of Immunology, 161, 6776-6783.

[13] Namangala, B., De Baetselier, P. and Beschin, A. (2008) Both Type-1 and Type-II Response Contribute to Murine Trypanotolerance. The Journal of Immunology, 71, 313-318.

[14] Kaushik, R.S., Uzonna, J.E., Zhang, Y., Gordon, J.R and Tabel, H. (2000) Innate Resistance to Experimental African Trypanosomiasis: Differences in Cytokine (TNF-alpha, IL-6, IL-10 and IL-12) Production by Bone Marrow Derived Macrophages from Resistant and Susceptible Mice. Cytokine, 12, 1024-1034. http://dx.doi.org/10.1006/cyto.2000.0685

[15] Nishimura, K., Hamashita, K., Okamoto, Y., Kawahara, F., Ihara, H., Kozaki, S., Ohnishi, Y. and Yamasaki, S. (2004) Differential Effects of Interferon-Gamma on Production of Trypanosome-Derived Lymphocyte-Triggering Factor by Trypanosoma brucei gambiense and Trypanosoma brucei brucei. Journal of Parasitology, 90, 740-745. http://dx.doi.org/10.1645/GE-211R1 
[16] O’Gorman, G.M., Park, S.D.E., Hill, E.W., Meade, K.G., Mitchell, L.C., Agaba, M., Gibson, J.P., Hanotte, O., Naessens, J., Kemp, S.J. and MacHugh, D.E. (2006) Cytokine mRNA Profiling of Peripheral Blood Mononuclear Cells from Trypanotolerant and Trypanosusceptible Cattle Infected with Trypanosoma congolense. Physiological Genomics, 28, 53-61. http://dx.doi.org/10.1152/physiolgenomics.00100.2006

[17] Paling, R.W., Moloo, S.K., Scott, J.R., McOdimba, F.A., Logan-Henfrey, L.L., Murray, M. and Williams, D.J. (1991) Susceptibility of N'Dama and Boran Cattle to Tsetse-Transmitted Primary and Rechallenge Infections with a Homologous Serodeme of Trypanosoma congolense. Parasite Immunology, 13, 413-425. http://dx.doi.org/10.1111/j.1365-3024.1991.tb00294.x

[18] Naessens, J., Leak, S.G., Kennedy, D.J., Kemp, S.J. and Teale, A.J. (2003) Responses of Bovine Chimaeras Combining Trypanosomosis Resistant and Susceptible Genotypes to Experimental Infection with Trypanosoma congolense. Veterinary Parasitology, 111, 125-142. http://dx.doi.org/10.1016/S0304-4017(02)00360-6

[19] Lutje, V., Mertens, B., Boulange, A., Williams, D.J. and Authie, E. (1995) Trypanosoma congolense: Proliferative Responses and Interleukin Production in Lymph Node Cells of Infected Cattle. Experimental Parasitology, 81, 154164. http://dx.doi.org/10.1006/expr.1995.1104

[20] Mertens, B., Taylor, K., Muriuki, C. and Rocchi, M. (1999) Cytokine mRNA Profiles in Trypanotolerant and Trypanosusceptible Cattle Infected with the Protozoan Parasite Trypanosoma congolense: Protective Role for Interleukin-4? Journal of Interferon \& Cytokine Research, 19, 59-65. http://dx.doi.org/10.1089/107999099314423

[21] O’Brien, O.J. (2008) Cardiac Troponin Is the Most Effective Translational Safety Biomarker for Myocardial Injury in Cardiotoxicity. Toxicology, 245, 206-218. http://dx.doi.org/10.1016/j.tox.2007.12.006

[22] Taiwo, Y.O., Nantulya, Y.M., Moloo, S.K. and Ikede, B.O. (1990) Role of the Chancre in Induction of Immunity to Tsetse-Transmitted Trypanosoma (Nannomonas) congolense in Goats. Veterinary Immunology and Immunopathology, 26, 59-70. http://dx.doi.org/10.1016/0165-2427(90)90132-C

[23] Herbert, W.J. and Lumsden, W.H.R. (1976) Trypanosoma brucei: A Rapid Matching Method for Estimating the Host's Parasitemia. Experimental Parasitology, 40, 427-432. http://dx.doi.org/10.1016/0014-4894(76)90110-7

[24] Sileghem, M., Flynn, J.N., Logan-Henfrey, L. and Ellis, J. (1994) Tumour Necrosis Factor Production by Monocytes from Cattle Infected with Trypanosoma (Duttonella) vivax and Trypanosoma (Nannomonas) congolense: Possible Association with Severity of Anaemia Associated with the Disease. Parasite Immunology, 16, 51-54. http://dx.doi.org/10.1111/j.1365-3024.1994.tb00304.x

[25] Flynn, J.N. and Sileghem, M. (1991) The Role of the Macrophage in Induction of Immunosuppression in Trypanosoma congolense-Infected Cattle. Immunology, 74, 310-316.

[26] Lutje, V., Taylor, K.A., Boulange, A. and Authie, E. (1995) Trypanosoma congolense: Tissue Distribution of LongTerm T- and B-Cell Responses in Cattle. Immunology Letters, 48, 29-34. http://dx.doi.org/10.1016/0165-2478(95)02437-9

[27] Taylor, K.A., Lutje, V., Kennedy, D., Authie, E., Boulange, A., Logan-Henfrey, L., Gichuki, B. and Gettinby, G. (1996) Trypanosoma congolense: B-Lymphocyte Responses Differ between Trypanotolerant and Trypanosusceptible Cattle. Experimental Parasitology, 83, 106-116. http://dx.doi.org/10.1006/expr.1996.0054

[28] Fartashvand, M., Sakha, M.G. and Saf, S. (2013) Elevated Serum Cardiac Troponin I in Cattle with Theileriosis. Journal of Veterinary Internal Medicine, 27, 194-199.

[29] Lobetti, R., Dvir, E. and Pearson, J. (2002) Cardiac Troponins in Canine Babesiosis. Journal of Veterinary Internal Medicine, 16, 63-68. http://dx.doi.org/10.1111/j.1939-1676.2002.tb01607.x

[30] Koutinas, C.O., Mylonakis, M.E., O’Brien, P.J., Leontides, L., Siarkou, V., Breitschwerdt, E.B. and Koutinas, A.F. (2012) Serum Cardiac Troponin I Concentration in Naturally Occurring Myelosuppresive and Non-Myelosuppresive Canine Monocytic Ehrlichiosis. The Veterinary Journal, 194, 259-261. http://dx.doi.org/10.1016/j.tvjl.2012.04.008

[31] Diniz, P.P.V.P., De Morais, H.S.A., Breitschwerdt, E.B. and Schwartzm, D.S. (2008) Serum Cardiac Troponin I Concentration in Dogs with Ehrlichiosis. Journal of Veterinary Internal Medicine, 22, 1136-1143. http://dx.doi.org/10.1111/j.1939-1676.2008.0145.X

[32] Paim, F.C., Duarte, M.M., Costa, M.M., Da Silva, A.S. and Wolkmer, P. (2011) Cytokines in Rats Experimentally Infected with Trypanosoma evansi. Experimental Parasitology, 128, 365-370. http://dx.doi.org/10.1016/j.exppara.2011.04.007 


\section{Submit or recommend next manuscript to SCIRP and we will provide best service for you:}

Accepting pre-submission inquiries through Email, Facebook, Linkedin, Twitter, etc A wide selection of journals (inclusive of 9 subjects, more than 200 journals)

Providing a 24-hour high-quality service

User-friendly online submission system

Fair and swift peer-review system

Efficient typesetting and proofreading procedure

Display of the result of downloads and visits, as well as the number of cited articles

Maximum dissemination of your research work

Submit your manuscript at: http://papersubmission.scirp.org/ 